\title{
ENTRE EL DESEO Y LA INVENCIÓN DEL SABER
}

Ramiro Martín Rojas

Instituto de Formación Docente Continua n.. 5 “José Eugenio Tello”, Argentina

\section{INTRODUCCIÓN}

Es un lugar común en los labios de muchos docentes la falta de deseo de aprender por parte de sus alumnos adolescentes. $Y$ esto no es muy lejano a la opinión de alumnos que al preguntarles por qué vienen a la escuela, o qué sentido tiene para ellos la enseñanza que se les proporciona, encogiéndose de brazos sólo responden: "no tenemos ganas de aprender".

Es un problema de motivación con la que se encuentran a diario los profesores, entonces se busca como acciones de modificación de esta problemática, el empeño por dar contenidos y actividades "significativas", utilizar los nuevos recursos de la información y la comunicación, y como resultados tenemos situaciones ambiguas, según sean los grupos con los que se encuentran los docentes. Durante el transcurso de una entrevista con una profesora de Filosofía de 2.. año de nivel Polimodal, me decía: "Podías entrar con un camión al curso y no pasaba nada".

La verdad que es una situación muy complicada, y de ahí nuestro interrogante: ¿cómo hacer para despertar en los alumnos el deseo de saber? En el camino de encontrar una respuesta a este interrogante, decidimos rastrear en el psicoanalista francés Jacques Lacan dónde estaría la clave para el desarrollo del deseo de saber.

\section{LA CUESTIÓN DEL DESEO DE SABER}

La posición de Lacan en torno al deseo de saber continúa la vertiente inaugurada por Freud, en tanto que la pulsión epistemofílica no es primigenia en el ser humano. Lacan radicaliza aún más esta postura pues, si hay algo en relación con el saber es el horror y no el deseo.

Lacan entiende por saber algo diferente al conocimiento y a la representación. En el seminario XVII señala que el saber es una cosa que liga un significante ( S1) a otro (S2). Esta relación está establecida en el inconsciente. Como sabemos, el inconsciente está estructurado como lenguaje, lo que conlleva que se trata más bien de un saber no-sabido, soportado del significante. Con esto Lacan profundiza a Freud en el sentido de relacionar Inconsciente a Saber, relación ya implícita en el término alemán que designa al inconsciente, unbewust.

Pero Lacan da un paso más allá, pues el inconsciente es un saber gozado y en cuanto tal no se quiere saber más, con la finalidad -como sostiene Lucie Wolf (1997)- de gozar tranquilo.

En este punto consideremos el lugar del saber. Es el lugar del Otro donde se posa el significante y también su falta en el orden del deseo, en tanto que en el Otro no hay un significante que nombre su deseo. Si el saber está en el Otro, se puede interpretar el significado de aprender, en el sentido de a-prenderlo del Otro. Ahora bien, ¿qué es lo que se encuentra en la sede del Otro y que produce en términos de Lacan una 
molestia? No es otra cosa que la ignorancia del Otro. A él se le supone un saber que no lo tiene, pues en realidad no sabe nada. (cfr. Encore: 123, 125)

Con estas tesis negativas en relación al saber pareciera que se cierra toda posibilidad de tematizar el deseo de saber. Aún más teniendo en cuenta que para Lacan el deseo de saber no conduce al saber. Sin embargo es posible un artificio, pues como dice Lacan "el saber se inventa". (Sem 21, clase 11).

Desarrollemos esta posibilidad de invención desde dos aspectos: 1) la respuesta del sujeto ante el deseo del Otro, es decir desde la demanda de amor; 2) el discurso, especialmente desde lo que Lacan denomina el discurso de la histérica y el de la universidad. Con esto dejamos la cuestión del deseo de saber y nos centramos en un dispositivo discursivo que posibilite la elaboración del saber.

\section{a) la respuesta del sujeto ante el deseo del Otro}

Vayamos al primer punto, y este consistiría en reflexionar desde la relación que establece el sujeto con el Otro.

En el seminario 21 Les non-dupes errent, puntualmente en la clase del 9 de Abril de 1974, Lacan señala un caso concreto, el de alguien que se somete a un examen para obtener una cátedra. Esto podría ser un ejemplo claro de deseo de saber. Sin embargo Lacan nos invita a reflexionar en otro sentido. El deseo de una cátedra universitaria, habría que contextualizarlo ante el deseo del OTRO. Un sujeto podría percibir que sumándose al discurso de la ciencia, encuentra un lugar en la sociedad. Concretamente Lacan señala que el sujeto descubriría al Discurso Universitario como instrumento de Poder. Por esta razón, el deseo de saber, si adquiere sustancia, es en relación al grupo social. (Cfr. ÍDEM). Lucie Wolf, interpretando el planteo de Lacan en este punto indica que el camino para dar lugar al deseo de saber en el sujeto, sería indagar los significante del Otro que han marcado la infancia del Sujeto, es decir preguntarse por el modo bajo el cual han sido ofrecidos al niño el saber, el goce y el objeto "a". (cfr. Wolf, 1997:103)

Si al deseo de saber lo encontramos en relación al deseo del OTRO, podríamos vincularlo en torno a la demanda de amor. Tomemos el caso de las preguntas que dirige el niño al Otro. En el seminario XXI Lacan hace la siguiente precisión: ante el OTRO, sede del Significante y de un Saber Supuesto, surgen una serie de manifestaciones de complacencia bajo la forma del por qué. Por un lado, por medio de las preguntas el niño trata de satisfacer lo que supone que el OTRO quisiera que preguntara. Por otro lado, en esta experiencia se trata de oír algo que da placer, de un actuar como si realmente se interesaran, y cuando saben aquello por lo que preguntan, lo reprimen. (cfr. IBIDEM) Se da entonces una experiencia de posicionarse ante el deseo del OTRO y a la vez de represión de un saber propio.

Un caso extremo de este posicionamiento ante el deseo del Otro por parte del sujeto, se da en la cuestión de la demanda. Para Lacan, hay una dialéctica entre demanda y deseo, lo que implica que no se identifican mutuamente. Es más, lo extremo está en que satisfacer la demanda puede implicar anular el deseo. El ejemplo de Lacan es el caso de la anorexia mental señalada en el seminario VIII "Le transfert". Para ejemplificar esto tomemos lo que pasa en el plano de la demanda oral. Ella -que es demanda de ser alimentado- es contemporánea a la demanda de dejarse alimentar. Hay una ambivalencia pues si el otro satisface la demanda se corre el riesgo de extinguir el deseo. Un deseo desborda a la demanda, entonces el sujeto rechaza la respuesta del otro como camino para salvaguardar el deseo. El sujeto cuando demanda pide que su demanda no sea satisfecha. 
La demanda oral está vinculada con la pulsión sexual pues se trata de unirse al cuerpo del otro, cuya expresión más radical se da en el canibalismo. En este punto Lacan señala que la libido sexual es un excedente que torna vana toda satisfacción de la necesidad ahí donde ella se ubica. Y si es necesario, rechaza esta satisfacción para preservar la función del deseo. (Sem. VIII: 244) ${ }^{1}$

En el caso de la anorexia mental consistiría en un rechazo a dejarse nutrir. La causa estaría en la presencia de un otro tan presto por responder a la demanda del sujeto que provoca así el rechazo de su don a condición de salvaguardar el deseo. Para nosotros esta es una observación rica en implicancia a los fines de nuestra investigación. Si partimos de un caso de estudio donde los alumnos se manifiestan impávidos ante sus profesores, tal vez una hipótesis explicativa de esta situación estaría dada en la modalidad del vínculo donde los docentes saturan con sus dones a sus estudiantes.

\section{b) Discurso y elaboración del saber}

En relación al segundo punto, es decir al discurso, Lacan señala que es el discurso de la histérica quien produce un hombre animado por el deseo de saber. ${ }^{2}$ El esquema del discurso de la histérica es el siguiente:

(Graf.1)

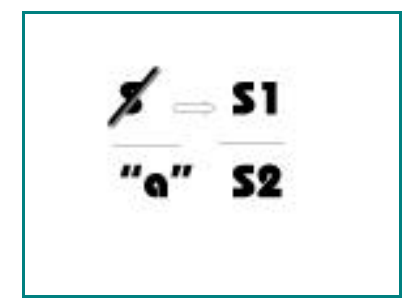

Los términos se leen de la siguiente manera:

- La S tachada significa el Sujeto,

- $\quad$ El S1 es el Significante Amo,

- $\quad$ El S2 es el Saber y

- a significa el objeto de deseo como plus de gozar

En los cuatro discursos estos términos ocupan los siguientes lugares:

(Graf.2)

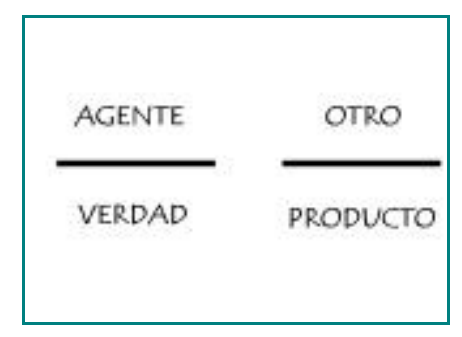

El grafo del discurso de la histérica se leería de la siguiente manera: El sujeto de deseo, se dirige a otro que sería el Amo y produce un Saber (S2), existiendo una impotencia en la relación entre saber y

\footnotetext{
1 “...la libido sexuelle est bien en effet une surplus., mais une surplus qui rend vaine toute satisfaction du besoin là ou elle se place. Et au besoin, ... elle refuse cette satisfaction pour préserver la fonction du désir. » (sem. XVII: 36)

2 "Nous voyons donc l'hystérique fabriquer comme elle peut, un homme -un homme qui serait animé du désir de savoir."
} 
verdad como a que sería la causa de deseo de la histérica. Lo que significa que a como causa de deseo y plus de gozar, queda sustraída al sujeto de deseo y de ahí la impotencia.

El sujeto histérico se presenta como identificado al significante de la falta, es decir al deseo insatisfecho. En tanto deseo insatisfecho se dirige al Amo. En esta relación entre Sujeto y Amo, representada en el plano superior del esquema, la posición del Sujeto está marcada por un deseo. Lo que quiere la histérica es un amo que no gobierne y sobre el cual reinar. (cfr. Sem. XVII: 150) Hay una posición ambigua, pues en primera instancia busca continuamente destituir al amo, desenmascararlo, constituirlo como sujeto de falta, para luego ser solidario a él, es decir lo mantiene como amo alienándose a su significante. Ahora bien, en esta posición lo que queda relegada a la impotencia es el a de la histérica, es decir aquello que causa su deseo no podrá alcanzar jamás el saber. Lacan hace una observación en este punto. La histérica, a su manera, realiza una especie de huelga, pues no libera su saber, en definitiva el saber lo produce el amo quien es puesto a trabajar por la histérica. (IDEM: 107)

Vayamos al discurso de la Universidad:

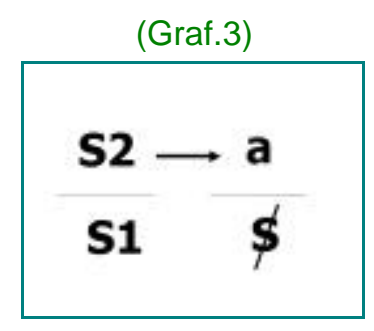

En el esquema el saber viene a ocupar el lugar del agente que se dirige al "a" para producir un sujeto. En este cambio, el saber ocupa el lugar del mandato. Es para Lacan un mandato imposible de desobedecer y que se formula como: "continúa siempre a saber más". ${ }^{3}$

El mandato se dirige al estudiante que viene a ocupar el lugar del a. Lacan juega con la homofonía del francés y habla de a-studé, lo cual podría indicar una connotación peyorativa ${ }^{4}$. La posición del $\boldsymbol{a}$ en el lugar del otro indica que es quien trabaja y la producción es la de un sujeto de deseo, y no la de un saber.

Ahora bien, ¿cuál sería la consecuencia de plantear la enseñanza desde la lógica del discurso Universitario? Como señalamos, lógicamente no se trata de la producción de un saber, aunque sí de un sujeto signado por su división. Por eso Lacan afirma: “...La enseñanza podría ser hecha para hacer una barrera al Saber". ${ }^{5}$ Por otra parte, Marcelo Antelo se pregunta si una enseñanza planteada desde la orden y el mandato, es más seguro que provoque el rechazo más que el Amor y el Deseo. (cfr. ANTELO, 2001:104)

Si el deseo pasa por el Otro, y como hemos afirmado sabemos que no hay nada como eso que llamamos deseo de saber en el sujeto entonces pensemos en la posición subjetiva que favorecería el deseo y la elaboración del saber.

\footnotetext{
${ }^{3}$ « Il est impossible de ne pas obéir au commencement qui est là, à la place de ce qui est la vérité de la science -Continue, Marche. Continue à toujours plus savoir. » (Sem. XVII : 120)

4 esta interpretación es señalada en la traducción del seminario 17 versión digital. La traducción de este seminario no consigna traductor, se basa en una versión de un Simposio del Campo Freudiano.

5 « c'est que l'enseignement pourrait être fait pour faire barrière au savoir » (LACAN, 1970)
} 
Posición subjetiva y elaboración del saber

Jaques-Alain Miller en su artículo "Cinco variaciones sobre la elaboración provocada"(1986) desarrolla un dispositivo lógico de elaboración del saber en base a la estructura de los cuatro discursos. Este artículo está contextualizado en un dispositivo ideado por Lacan para la producción del saber en psicoanálisis llamado "cartel". En líneas generales el cartel es un dispositivo grupal constituido por cuatro personas y un "mas uno", los cuales trabajan sobre un determinado tema de investigación. La función del "más uno" es evitar el efecto de grupo en el cual el saber quede estancado, cumple así el rol de descompletar al grupo.

En el contexto del artículo, la producción del saber sería del orden de la elaboración. Para Miller se trataría de provocarla, pues naturalmente no hay una vocación al trabajo. En la apropiación de Miller a los esquemas de los cuatro discursos, los lugares son nombrados de la siguiente manera:

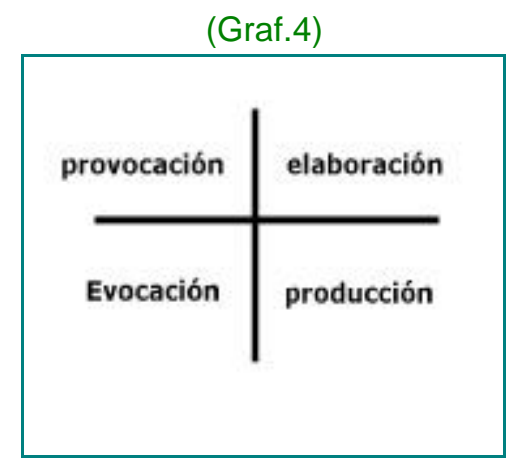

En el discurso Amo la provocación es una llamada al trabajo, pero si en la enseñaza se solidifica esta estructura, lo que se pone a trabajar es el saber que está ahí, y no un resultado de saber. Lo mismo pasa en el discurso del analista

(Graf.5)

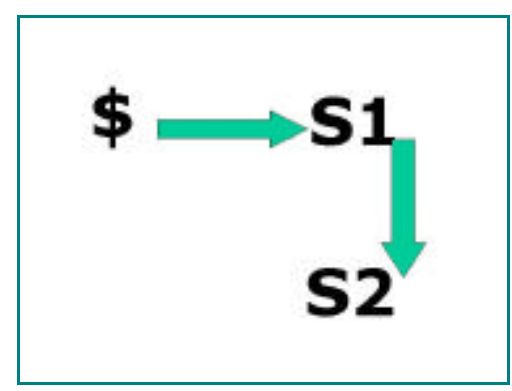

En este discurso lo que se trata es de la denuncia de un significante amo, y no de la producción de un saber. Por eso Miller propone recurrir a la estructura del discurso de la histeria, lo cual implica que el lugar del provocador esté ocupado por un sujeto de deseo.

Miller manipula (sic) la estructura del discurso histérico de la siguiente manera: 


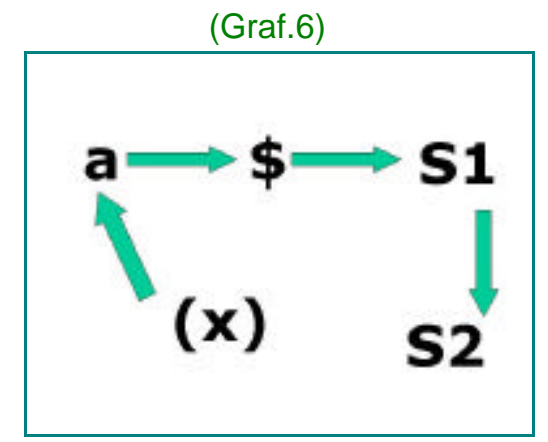

Esta modificación tiene las siguientes implicancias. Pimeramente hay una ascesis en el agente provocador, pues oculta a objeto causa de deseo. En el gráfico, la presencia de la " $x$ " entre paréntesis significa que el efecto de atracción no recae en su presencia, sino que el agente provocador se siente a su vez causado.

Segundo, la presencia del agente provocador no es sólo de quien hace trabajar como en el caso de la histérica, sino que él también produce, es decir, se pone a trabajar. En este sentido y parafraseando a Miller, al agente provocador le corresponde tomar a su cargo la división subjetiva. Para Miller esto significa que los miembros del dispositivo de elaboración del saber, no tienen que abandonarse a la asociación libre, o a la denuncia de los significantes amos. Esto no llevaría a la producción del saber.

Tercero y como corolario de los dos puntos anteriores, una cuestión importante para la producción del saber es que los miembros del dispositivo se presenten como amos, es decir elaboran un saber desde un rasgo propio. Esta sería la tarea del agente provocador, hacer que los integrantes trabajen desde una insignia propia, llámese a esto, sus concepciones previas, su interés particular por la temática, o una interpretación propia. Entonces, si cada miembro del dispositivo actúa como amo, del lado de la elaboración no tendremos un único $\mathrm{S} 1$, sino un enjambre ${ }^{6}$. Lo que llevaría desde la posición del agente a una lógica colectiva de producción del saber.

Miller completa su gráfico de la siguiente manera:

(Graf.7)

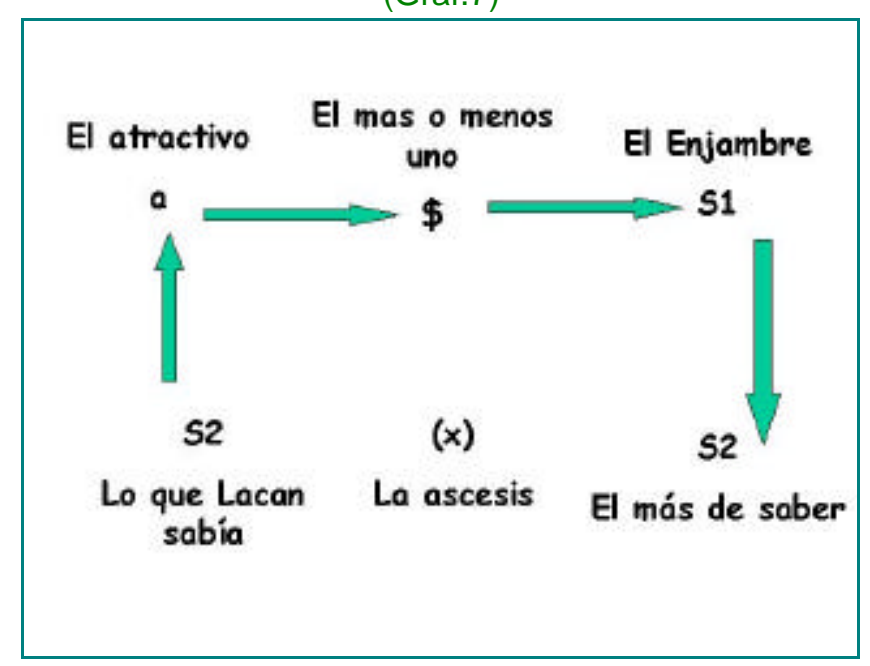

\footnotetext{
${ }^{6} \mathrm{~S} 1$ y enjambre( essaim) en francés son homofónicos.
} 
En esta apropiación vemos que el lugar del atractivo, está del lado de la región del conocimiento, del cual el agente provocador vendría a ser su representante. En este caso la teoría de Lacan quien produciría el efecto de transferencia. En relación a la transferencia con el enjambre de S1 (Miller recurre a la metáfora de las abejas que trabajan), se habla de transferencia de trabajo. En el esquema, la clave está en la posición del agente provocador en tanto no atrae sobre sí el efecto agalmático, sino que lo remite a otra parte, como podrían ser Freud, Lacan, Platón, Piaget, Vigotsky...

\section{MODALIDADES ENUNCIATIVAS DE DOCENTES EN UN CASO DE ESTUDIO}

Hecha esta primera apreciación teórica referente a la posibilidad del deseo de saber y, especialmente a la posibilidad de un dispositivo que sea de invención del saber, recurrimos a grabaciones de clase de un curso de segundo año de nivel polimodal de una escuela ubicada en los márgenes de la ciudad de Salta.

El curso tenía la particularidad de que a pesar de que establecía un vínculo muy positivo con sus profesores se observaban fenómenos relacionados con el fracaso escolar, como la repitencia, la sobreedad, el poco interés por el estudio.

En este curso decidimos registrar magnetofónicamente una clase de 30 minutos de cada uno de los profesores, a fin de determinar qué tipo de modalidades enunciativas establecían con sus alumnos. Antes de señalar los resultados del trabajo de campo en este sentido, refirámonos brevemente a lo que se entiende por modalidad enunciativa.

\section{El concepto de modalidad enunciativa}

Para María Isabel Filinich, el concepto de modalidad implica la presencia de dos predicados, uno de los cuales incide sobre la significación del otro. (Cfr. Filinich,2001:85).

Kerbrat-Orechioni (1986), distingue las modalidades de la enunciación de las modalidades del enunciado. Las modalidades de la enunciación define la modalidad en relación con el sujeto hablante y caracteriza la forma de comunicación entre enunciador y enunciatario. (imperativa, interrogativa, declarativa, etc.) (Cfr. Idem)

En cambio las modalidades del enunciado se refieren al sujeto del enunciado y caracterizan el modo con el que el sujeto sitúa la proposición en relación a la necesidad y posibilidad, a la verdad o a los juicios de valor.

Lo importante es que en estas modalidades, la del enunciado y la de la enunciación se indica la posición del sujeto. Esta posición es localizable en toda secuencia enunciativa a través del modo verbal, la construcción sintáctica (como las interrogaciones) o los lexemas afectivos o evaluativos.

El sujeto de la enunciación, el yo, es un shifter, es decir que a lo largo de una secuencia enunciativa va ocupando diferentes posiciones y no de una manera unívoca. Para Kerbrat-Orechioni, se producen procedimientos de conmutación mediantes los cuales el yo del discurso nunca alcanza una unidad, sino que despliega una polifonía.

Kerbrat-Orechioni menciona la importancia de la competencia modal que equivale a un complejo de modalidades compatibles dirigidas al hacer de un Sujeto. Este complejo de modalidades que están 
organizadas jerárquicamente, constituirá la competencia modal fundada sobre un querer-hacer o un deberhacer que rigen un poder-hacer o un saber-hacer.

Para Greimas es el querer y/ o deber y/ o poder y/ o saber hacer del Sujeto que presupone su hacer operador. Podría definirse como el sincretismo de las modalidades del querer+deber+poder+saber decir. (Cfr. Kerbrat-Orechioni: 1986)

Para el análisis de los discursos de los docentes, hay dos conceptos que nos resultan claves: el de las modalidades veridictivas y el de las modalidades factitivas o de la manipulación.

Las modalidades veridictivas se caracterizan por ser enunciados de estado que modifican a otros enunciados de estado. En este sentido la categoría de veridicción se compone por el esquema de la manifestación (parecer / no parecer) y por el esquema de la inmanencia (ser/ o no ser). Con esto, la operación cognitiva en tanto producción de verdad realizada por el enunciador, consiste más que en producir discursos verdaderos, en generar discursos que produzcan un efecto de sentido, al que podemos llamar verdad.

Esta operación discursiva depende de un contrato entre enunciador y enunciatario por el cual se manipulan estados de veridicción. El enunciador busca en el enunciatario la adhesión a su saber, por medio de un hacer persuasivo. Desde el enunciatario mediante un hacer interpretativo se adherirá o no a la propuesta del enunciador. Cuando el objeto-saber se comunica tenemos de parte del enunciador las estrategias cognitivas de la persuasión y de parte del enunciatario las de la interpretación.

El objeto-saber en el intercambio comunicacional queda modalizado por el hacer persuasivo del enunciador y por el hacer interpretativo del enunciatario. Del lado del enunciador hay un hacer creer y del lado del enunciatario la posibilidad o no de creer.

La modalidad factitiva se da cuando un enunciado modal que tiene por predicado hacer y por sujeto S1, modifica a otro enunciado de hacer que tiene por sujeto a S2. Entre enunciador y enunciatario se intercambio objetos cognitivos, es decir saberes. La modalidad factitiva es una modalidad de manipulación, pues se trata de un hacer que modifica a otro hacer. Si en el intercambio comunicativo el enunciatario está en una posición de libertad, pues tiene la posibilidad o no de aceptar o rechazar el contrato propuesto por el enunciador, entonces se produce la comunicación. Pero si el enunciatario no puede aceptar el contrato propuesto, estamos ante una comunicación manipulatoria.

Kerbrat-Orechioni menciona cuatro figuras de transferencia de la competencia modal. Cuando la manipulación es del orden del hacer-hacer, se habla de la intervención. Si en cambio se trata de un nohacer- no-hacer se caracteriza como dejar hacer. El impedimento en cambio es del orden del hacer-nohacer, y por último, cuando se da un no-hacer-hacer, estamos frente a la no-intervención.

Además estas figuras juegan con las siguientes posibilidades del lado del enunciador manipulador, y del lado del enunciatario manipulado.

Desde el enunciador, la manipulación puede basarse en el poder, entonces tenemos la amenaza o la tentación al enunciatario. En cambio si, la manipulación se basa en el saber, el enunciador busca provocar, es decir, dar una imagen negativa de la competencia, o bien seducir, acción que consistiría en brindar una imagen positiva de la competencia del enunciatario. 
Desde la posición del enunciatario manipulado se pueden dar las siguientes opciones. El enunciatario puede estar modalizado por un deber hacer y por lo tanto actuará porque se siente o bien intimidado o bien provocado. En cambio si está modalizado por un querer-hacer, el enunciatario actuará pues se siente tentado o seducido.

Por último, el enunciatario manipulador es también un ser de pasión. Su acción puede estar modalizada en el nivel de la enunciación por un deber o un querer, y en el nivel del enunciado (o de la efectuación) por un poder o un saber. Si quiere realizar algo, pero no puede, experimentaría en todo caso una frustración, en cambio si puede y lo realiza experimentaría la satisfacción.

\section{El discurso pedagógico}

A partir de los análisis lingüísticos de los registros de clase, encontramos que la modalidad enunciativa que prevalece en la mayoría de los discursos es la manipulación. Se trata de un hacer que modifica a otro hacer. Lo significativo del caso es que podría pensarse al discurso pedagógico como una modalidad veridictiva, en donde el enunciador construye su discurso como creíble. En esta línea podría estar el discurso de la profesora de historia, quien recurre a una variedad de artificios retóricos, como la enunciación enunciada y la enunciación citada, para ilustrar la temática que enseña. Sin embargo, ella interviene desde la modalidad factitiva en tanto que le pide a sus alumnos que copien, que realicen una tarea, etc.

En este sentido el discurso pedagógico se presenta no sólo como una variedad del discurso universitario, sino también del amo. No es sólo saber lo que se le ordena a los estudiantes, sino también escribir, sentarse, callarse, hablar... con esto se actúa sobre la mente y el cuerpo de los individuos.

La cuestión está en que desde esta posición es difícil que se logre elaborar un saber. Parafraseando a Lacan, la enseñanza se constituye en una barrera que impide el saber. (cfr. 1970)

Prácticamente los discursos registrados se quedan en la reproducción de un saber y no en un ir más allá.

Si intentamos ver qué indicios de la posición subjetiva del docente como agente provocador aparecen en el material recopilado, es interesante la posición del profesor de tecnología. A través de la figura retórica de la ironía se constituye en un agente provocador. Continuamente está provocando, comportándose al principio como un amo que llama al trabajo, con enunciados regidos por la forma impersonal del verbo "hacer". Pero, en una segunda instancia, construye la figura de un enunciador tramposo al cual los alumnos tienen que responder con una actitud crítica.

Veamos la siguiente secuencia:

74. El scanner ¿para qué sirve?

75. Para ingresar información

76. ¿qué tipo de información? (responden los alumnos)

77. fotos, ¿qué más?

78. textos 
79. O sea que el Scanner sería más o menos como una fotocopiadora donde ustedes ponen la imagen que quieren scannear.

80. esa imagen es transferida a la computadora a través de un programa

81. pueden sacarle partes, agregarle cosas, o bien scannear textos

82. pasar de lenguaje escrito a la computadora y ver el resultado en (expresión inentendible)... ¿si?

83. Entonces ¿nos permite sacar información el Scanner?

84. ¿nos permite ver información?

85. ¿Sí o no?

86. o ¿dónde la vemos?

87. Entonces nos permite el Scanner ver información ¿o no?

88. Noooo

Lo relevante de esta secuencia es que el profesor introduce por medio de sus preguntas opciones falsas, y por ende contradictorias con lo que ya había enunciado, sobre las que tienen que optar los estudiantes. Los pone así en situación de equivocación. Se podría pensar que en esta secuencia se proyecta la imagen de un enunciador tramposo y un enunciatario ingenuo que acepta como ciertas las opciones que le da la autoridad.

Sin embargo, en el enunciado № 75 el profesor da la clave de la respuesta que amplía en los enunciados posteriores. Esto mostraría más que nada la imagen de un enunciador sagaz que quisiera tal vez provocar un enunciatario perspicaz con la competencia necesaria de captar la trampa tendida y, $\sin$ embargo esta intención queda fallida por lo que se patentiza una imagen negativa de la competencia del enunciatario. De ahí la reacción del profesor, la negación enfatizada por el tono y la prolongación de la vocal en el lexema "no" como reacción a sus estudiantes.

En esto encontramos una diferencia con los modos de provocar de, por ejemplo, la profesora de economía. Desde la lingüística la provocación consistiría en brindar una imagen negativa de la competencia del enunciatario. En el profesor de tecnología la provocación se contextualiza más en un orden simbólico de adquisición de un saber. A lo sumo la estrategia discursiva del profesor figura la imagen de un alumno que se deja llevar por la mera respuesta irreflexiva. En cambio en la profesora de economía la provocación busca más que brindar una imagen negativa de la competencia del enunciatario, es decir negativizarlo como sujeto.

Como es lo que sucede en la siguiente secuencia:

33. ¿ ¿No se acuerdan de nada del trabajo práctico?

34.- Ustedes hacen eh... los trabajos como loros y no se acuerdan casi nada..

35.- Contestan (con) las palabras textuales del libro y después no saben qué es lo que han contestado.

36. - yo los tengo ahí para corregir el trabajo, pero deberían acordarse

y en el enunciado № 139 : 
"Los veo con pocas ganas de trabajar"

En estos enunciados a la imagen de una enunciataria que exige memoria -es significativo que el verbo acordar aparece en tres enunciados de cuatro-, le corresponde un enunciatario en falta a esa exigencia y que es comparado con un animal. Además la falta de memoria se debe a que los estudiantes no han realizado un trabajo de comprensión de lo que leyeron. El enunciador, mediante su señalamiento pone así en falta al enunciatario.

En el enunciado № 36 la profesora afirma que es ella quien tiene los trabajos y que todavía no han sido corregidos, y que a pesar de esto, el uso en la oración subordinada de la conjunción adversativa pero y el verbo deber en tercera persona del condicional, mantiene la obligación de parte de los alumnos, y por lo tanto remarca su ser en falta.

Ahora bien, llevemos nuestra atención al enunciado № 61 :

"no... en realidad lo último que hicieron fue el trabajo práctico que me entregaron la semana pasada y que todavía yo no se los he entregado a ustedes, así que empecemos de nuevo..."

A nivel del significado, en esta oración se afirma que el trabajo práctico fue realizado hace ya una semana y que al presente no ha sido corregido por parte de la profesora. Considerar este dato nos lleva a pensar que la imagen de un enunciatario que no tiene una capacidad grande de memoria. Además la profesora sólo señala la falta en sus enunciatarios y no hay sesgo alguno de reconocer lo que sería una falta propia por, no haber corregido en una semana los trabajos de sus estudiantes. Se coloca así en el lugar imaginario del saber y la obligación.

\section{CONCLUSIÓN}

En estos tiempos el hecho de enseñar y aprender se convirtió en una cuestión compleja, especialmente por las problemáticas propias de nuestra época y a la que tanto alumnos como profesores no son ajenos.

Una reacción podría ser diseñar un nuevo ideal de enseñar y de aprender. En este punto podemos plantear que el docente tenga sobre sí la tarea de crear el deseo de saber. En este sentido la tesis de Lacan son importantes porque el deseo depende de circunstancias subjetivas que están en el espacio de la intimidad de cada sujeto, y de la cual sólo él es responsable.

Sin embargo y parafraseando a Lacan cuando dice que de nuestra posición de sujetos somos los únicos responsables, podemos dirigir nuestra atención a una reflexión sobre la posición que tiene el docente en el dispositivo de enseñanza.

Tal vez así, abriendo el espacio a una docta ignorancia, será posible, dejar un lugar para el saber.

\section{BIBLIOGRAFÍA}

ANTElo, Marcela (2001): "El caso del fracaso escolar" en SeVILLA, Mónica (comp.) Temas cruciales III: fracaso escolar. Atuel. Bs.As.

BLANCHARD-LAVILLE, Claudine (1996): Saber y relación pedagógica. Novedades Educativas. Bs. As.

- (1998): "En los orígenes de la capacidad de pensar y aprender" en BEILLEROT, acky et all. Saber y relación con el saber. Paidos educador. Bs. As 
BLANCHARD-LAVILLE, Claudine y BERDOT, Pierre: "La relación con el saber del docente de matemáticas en situación didáctica" en BEILLEROT, JackyOp. Cit

CORDIÉ, Anny (1994): Los retrasados no existen . Nueva Visión, Bs. As.

— (1998): Malestar en el docente. Nueva Visión. Bs. As.

FERNANDEZ, Alicia (1987): La inteligencia atrapada. Nueva Visión. Bs. As.

— (2000): Psicopedagogía en psicodrama. Nueva Visión. Bs. As.

— (1992): La sexualidad atrapada de la señorita maestra. Nueva Visión. Bs. As.

— (2000): Los idiomas del aprendiente. Nueva Visión. Bs. As.

FERRER, María Cristina y SÁNCHEZ LANZA, Carmen (1996): La coherencia en el discurso coloquial. UNR Editora. Rosario.

FILINICH, María Isabel (2001): La enunciación. Eudeba Bs. As. 1ª edic. 4ª̣ reimpresión.

* FReUd, Sigmund, trad. por LOPEZ-BALlesteros y DE TORRES, Luis (1981): "Sobre la psicología del colegial" en Obras Completas. Biblioteca Nueva. Madrid.

× "La dinámica de la transferencia" (Op. Cit)

× "Recuerdo, repetición y elaboración" (Op. Cit)

× "Lección XXVII: La transferencia" (Op. Cit)

* "Observaciones sobre el amor de transferencia" (Op. Cit)

× "Contribuciones al simposio sobre el suicidio"

— (1996): "La metamorfosis de la pubertad" en Los textos fundamentales del psicoanálisis. Altaya. Madrid

FREDA, HUGO: "el adolescente freudiano", no se consigna año de edición ni editorial

FRIGERIO, Graciela (1992): "Obstinaciones y estrategias, fracaso escolar y sectores populares en Argentina". en Propuesta educativa año 4 №6 marzo. Bs As.

KERBRAT-ORECCHIONI (1986): "La enunciación de la subjetividad en el lenguaje" Hachette. Bs. As.

LAVANDERA, Beatriz (1985): Curso de lingüística para el análisis del discurso. Centro Editor de América Latina. Bs.As.

LAPLANCHE, J y PONTALIS, J-B (1987): Diccionario de psicoanálisis. Barcelona. 3를 Edic. y 2ª reimpresión

GOETZ, J.P y LECOMPTE, M.D. (1988): Etnografía y diseño cualitativo en investigación educativa. Morata. Madrid

LACAN, Jacques (1970): Las formaciones del inconsciente. Nueva Visión. Bs. As.

Seminario IV La relación de objeto Edición digital

× Le SÉminaIRe VIII Le TRANSFert (1960-1961) SeUIL. PARIS 1991

$\times \quad$ LE SÉminaIRE XI LES QUATRE CONCEPTS FONDAMENTAUX DE LA PSYCHANALYSE (1964) DU SEUIL. 1973

× LESÉmINAIRE XVII “L' ENVERS DE LA PSYCHANALYSE”(1970) DUSEUIL 1991 


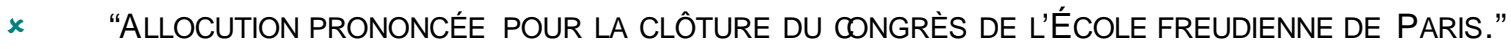
1970-04-19 EN WWW.ECOLE-LACANIENNE.NET

* LESÉminAIRE XX ENCORE (1973) DU SEUIL 1975

$\times \quad$ LESÉMINAIRE XXI LES NON DUPES ERRENT (1974) EDIC. DIGITAL

MILLER, J-A:“Cinco variaciones sobre el tema La Elaboración Provocada”. Texto disponible en www.eol.org.ar

— (1992): Introducción al método psicoanalítico. Eol. Paidós. Bs. As

— (1996): Elucidación de Lacan Eolia Paidos. Bs. As.

KORNBLIT, Cecilia (2000): "Entre la demanda y el mandato" en WWW. xpsicopedagogía.com.ar

PLATÓN (1970): El Banquete. Ed. Gredos. Madrid

SEVILLA, Mónica (2000): "Los recorridos escolares". en Fort-Da. №4 Agosto 2001. en WWW. fort-da.com.ar

STAKE, R.E (1998): Investigación con estudio de casos. Morata Madrid

STRAUSS, Marc: "La verdadera función del padre es unir un deseo a la ley". en A.A.V.V. Presentación de Lacan. Bs. As. Ed. Manantial

VERÓN, Eliseo (1983) : "Esta Ahí Lo Veo, Me Habla"

Revista Comunicativa № 38, Enonciation et cinéma, Seuil, París. Traducción realizada por María Rosa del Coto. Texto disponible en www.biblioteca.org

- (1994): Universidad de París VIII. "De l'image sémiologique aux discursivités. Les tempos d'une photo” París, Hermes, no13-14 : 45-64. trad. como “Espacios Públicos En Imágenes”. Traducido del francés por Julián Gorodischer. texto disponible en www.biblioteca.org

- (1985): «El análisis del "Contrato de Lectura", un nuevo método para los estudios de posicionamiento de los soportes de los media", en "Les Medias: Experiences, recherches actuelles, aplications", IREP, París. Texto electrónico disponible en: $\underline{w w w . b i b l i o t e c a . o r g}$

Wolf, Lucie (1997): "Qué Deseo de Saber" en El niño y el lazo social. II Jornadas del Instituto del Campo Freudiano. Atuel. Bs.As. 


\title{
Contactar
}

Revista lberoamericana de Educación

\author{
Principal OEI
}

